\title{
Applied Sociology and Institutionalised Professionalism Some Reflections on the Pragmatics of Child Care in Developing Societies. An Adaptation of Maslow's Hierarchy of Needs and the Bureaucratic Imperative
}

\author{
R.E.S.Tanner \\ The Footprint, Padworth Common, Reading, Berks. RG7 4QG, United Kingdom \\ Telephone: 0118-9701190; E-mail: restanner@kutkai.fsnet.co.uk
}

KEYWORDS Poverty; stages; professionalism; institutions; costs

ABSTRACT Poverty is so widespread that there seems little rational hope that professional welfare schemes based on western models can do more than mitigate extreme situations. There is a need for the acceptance of down-up social practices which do not require either funding or external supervision.

\section{INTRODUCTION}

Child care and the whole question of child rights would appear to share many of the characteristics of religious requirements. General impersonal regulations with which most people in all cultures would agree to be reasonable necessities for living in families, communities and as citizens. The downside is that these requirements are only followed spasmodically when the economic situation and social environment allows people to follow them. They are regularly broken when there are no social supports and controls present.

Attempts to reach international and crosscultural agreement on what these standards should be leads inevitably to general definitions and because of the complexity of cultures they tend to be of very limited usefulness (Geertz, 2000: 134-5). It would be necessary to provide regulations and rights to cover polygyny, polyandry, matrilineal and patrilineal, patrilocal, matrilocal systems, extended family, joint household families, single parent, remarriage from divorce and widowhood, serial monogamy, homosexuality and the levirate, apart from many children families, two child siblings and the 'Little Emperor' single child Chinese situation; such a list of social variations involving children would be virtually endless.

Political idealism has often been based on the western dominance of international bodies has tended to tie standards of care towards ethical obligations to the child rather than that of the child to the community. The obligations of society to provide for children as individuals rather than to stress the obligations of children towards their care providers and the social environments of which they are and must remain a part.

This is exemplified by numerous studies of child labour particularly in Asia where children work to help their families survive in urban and peri-urban environments and in subsistence farming generally in which children as a matter of course start working from about the aged of five years

It may seem to some that these potential rules stating that children have certain natural rights may be starting at the wrong end of the problem. Rights follow from other factors which enable rights to exist; they cannot exist on their own by reason of their 'obvious' virtue.

It is proposed therefore to look at the conditions in which it is theoretically possible to consider children as having rights using Maslow's hierarchy of needs (Maslow, 1987). This would provide a cross-cultural framework which at least partially ignores cultural, political, economic and religious differences, and to consider these as involving a clash of interests with the professionalisation of child care.

Secondly to examine the conditions under which standards of child care can become operative and indeed supervised in any community. In this it would seem reasonable not to start with the assumption that national standards can be enforced because it is the law. Attempts which are made to put in place a superstructure of supervision and responsibility are often costly and experienced as interference by outsiders. 
Planning should start from the knowledge of how much money is available for social welfare projects, how many hours of work can be expected from those involved in contact with and out of contact with childhood situations. Since this is usually minimal in terms of what is thought to be required, what can be done through rather than with the communities in which children exist. Professional care supervisors and providers have the statutory importance of their work as an important stimulus to maintaining and keeping intact their professionalism.

\section{THE HIERARCHY OF POSSIBILITIES FOR CHILDCARE}

Maslow suggested that there was an hierarchy of needs; physiological, safety, belongingness and love, esteem and self development. An hierarchy in which each stage has to precede before subsequent ones can appear in which the higher needs were less imperative showing greater social environment efficiency, less urgent subjectively, but producing more desirable subjective results, greater health ward trends, more preconditions requiring better outside conditions, wider circle of emotional identifications, desirable civil and social consequences, and greater individualism.

\section{Stage One: Safety}

Few societies outside the Western world and North America have the resources to cope with national and natural disasters. These are likely to affect children, not so much as to whether they can survive on their own, but whether their 'social owners' see them as useful resources which matters in the sense of adults depriving themselves of some supplies in order for their children to survive The comparison here is to the survival of the elderly who similarly have to be considered as even less useful in functional terms.

In considering the period since the end of WW2, there have been prolonged civil wars in Sri Lankha, Malaysia, Myanmar, Eritrea, Ruanda, Zaire, Liberia, Maputo, Angola, Sudan and Afghanistan. Famine again in China, Ethiopea and the prolonged droughts in sub-Saharan Africa as well as the Maputo floods and a series of earthquakes. The migration of large populations over the newly defined border between Pakistan and India in1947-8, and because of civil wars, refugees in enormous numbers are a feature of contemporary global life. This has created a professionalised and permanent industry. All these situations have provided mass misery, fear and deprivation that welfare agencies can only ameliorate

In these situations which may last for years and in some cases result in the destruction of whole communities with little possibility of their reconstitution, the main reaction is flight, which is often delayed until it is too late. The line of flight is littered with the bodies of children and the elderly who can no longer be carried by the surviving somewhat fitter adults. The healthier people from their moral beliefs, often delay in order to help their dependents, as in the mass exodus of Indians over the mountains out of Burma in 1942 when men stayed with their families instead of perhaps taking one child with them and surviving. This often results in a higher death rate overall and in particular the deaths of those of those needed to reconstruct their society.

Since the national governments have in effect been overwhelmed, if in fact they ever had more than titular control within their boundaries, such as Liberia and Chad, little can be provided to overset these social disasters. International aid cannot be provided in time because of the safety of its personnel, and the possible need for armed intervention. There is also the uncertainty of what is required and where, apart from the problems of whether donor governments want to use their revenue in this manner. The fog of war is a reasonable descriptive phrase covering these situations.

\section{Stage Two: Physiological Survival}

Once their safety has been to some extent assured, these survivors move on to food and water requirements as well as shelter Again the governments concerned may not have the means to offset these disasters and for reasons of national dignity may be unwillingly to call in international agencies to cope. Refugee camps may have sudden populations equivalent in size to small cities as the one in Ngara,Tanzania created by Ruanda refugees fleeing from HutuTutsi genocide. The facilities to save children may be quite inadequate as the agencies trying to help are often overwhelmed.

When such situations involve hundreds of thousands of people, providing aid is a major logistic exercise requiring staff work of a high 
quality and enormous expense. Donor countries may be unwilling to underwrite this expense on more than a temporary basis. Helping a few people depicted on television is seen as a reasonable emotional reaction but the extent of these massive miseries succeeding one another with almost monotonous regularity has led to an emotional deadening among donors as individuals as well as donor countries and institutions.

In these situations mothers may not be able to breast-feed their children, while their cessation of menstruation prevents the conception of replacement children. Although the children get some priority for food, particularly when they are with their mothers, there is often the question of providing medical help as well. In these situations children are perhaps an asset in getting food for the adults carrying them. Older children become adept thieves and scavengers in their need for food to survive such as the so-called street children of Brazil.

\section{Stage Three: Subsistence Level}

Most societies with rapidly growing populations, are subsistence ones depending on the annual cycle of rain which cannot be assured. Even in 'good' years the diet of children fluctuates perhaps being adequate after the harvest and increasingly inadequate between times so that no child is likely to have the regular and regulatable diets of the well-to-do middle class urban populations. They are likely to be underfed one year in five with the cornea rings showing this, and the majority will be suffering from some forms of malnutrition and ill-health.

The children in the towns are not likely to be any better off as most employment is irregular and likely to be on a day to day basis. In both situations the children are likely to be seen as assets in so far as they can contribute to the livelihoods of their guardians and most will certainly be working both in and outside the house by the age of five years. In some countries such as Zambia, it is now generally accepted that development in terms of acquiring western standards of living is not going to happen and that there is a reversion to reliance on subsistence farming. (Fergurson, 1999).

In this stage children become useful, a resource which those related to them recognise as worth preserving. While female infants at birth may have a lower value than male, as they grow older the preservation factor is reversed and girls become more valuable domestically and commercially (Whyte,1997).

In Zambia in $200180 \%$ of the population were classified as poor out of which $59 \%$ were stated to be 'core poor'(Hansen, 2003)and many countries are in the same range of having a majority of the population defined as poor, this is the overall social welfare situation within which planning has to be carried out. Such situations are so widespread as to be beyond the capabilities of these governments to cope financially despite legislation covering these needs as a national policy in line with international standards.

\section{Stage Four: Innovation and Individualism}

Individuals with assured economic and social positions may start choosing certain aspects of child care as their particular concern Some such as the police officer in southern India who devoted himself to saving girl babies from possible infanticide Others with 'spare-time' and perhaps 'spare-money' take up particular aspects of child care by creating branches of concerned organisation such as Save the Children and others non-governmental organisations with their ability to get international support in funds, personnel and training, are active in many fields of child support.

\section{Stage Five: State Concern for Child Care}

Interests of individuals and non-governmental organisations in child care become national concerns when there is sufficient tax revenue to implement a policy with staff and institutions and a public opinion that accepts the diversion of public revenue to these ends.

We can conclude that at each stage someone has to make difficult decisions on a whole range of issues involving children who may be too young or too handicapped to help themselves or to get help from their guardians; whether children should be employed and thus contribute to their own survival rather than just being a drain on their guardians' resources. These decisions are a combination of economic, social and belatedly moral issues.

A survey of Uganda in the mid 1960s before the Amin regime and the civil war, disclosed that a quarter of a million people were considered handicapped by their families and unable to contribute fully to their families' survival. The government accepted the report but in effect 
stated that it did not have the resources to do much beyond what was already being done by non-governmental organisations To what extent will the allocation of resources for children harm others in the extended or nuclear family and what are the limitation of these resources. The political return on caring for children comes decades after the expenditure on them while other expenditures earns much quicker political returns.

\section{THE QUESTION OF COST EFFECTIVENESS}

Let us start with the assumption that no government, developing or developed, has the political will or the human and material resources to ensure that children enjoy their hypothetical rights or indeed the minimum conditions for a reasonable childhood. To even think in such universal terms is an emotionally motivated ideal when every society has impoverished minorities and substantial numbers of disturbing cases of mistreatment.

Apart from the political limitations that children have no votes and money is not going to be spent on them to the exclusion of popular themes such as subsidies for food and health services and for the maintenance and support of the state. It would seem that child care supervision comes down to two permanent restrictions.

Firstly the limitations of finance for the creation and continuance of supervising agencies. The professionals involved are social outsiders, in many cases what might be called internal expatriates by language, caste, class, education and tribe and they are expensive to hire and keep employed. The paid for time on the job in direct contact with the situations of children cannot be all that high a proportion of costs. The cost of any child care agency includes training, travel, pensions, office support and record keeping, holidays, sick benefits, staff turnover and a 40 hour week.

Secondly the limitations of the time provided by involved personnel 'getting to know' the numerous people involved with and responsible for particular children who have a social rather than a legal right to be consulted. This is time consuming in any culture and has no parallels at all to the clinical assessments of medicine. An hour in such situations may be no more than the politeness of commonplace introductions. Finding out what is going wrong in a child's life is time consuming enough but to this has to be added the time spent in trying to engineer an improvement in any child's situation. Invoking the law is perhaps a sign of failure.

In such situations it is not the time spent talking which consumes the weekly time available budget but the additional time spent putting interviews into written records against the possibility of legal action. The need for the recorders to protect themselves against accusations of professional incompetence and the inevitable fact that few problems will be dealt with from start to finish by a single person. In effect most cases are dealt with by informal committees with changing members. The mere whisper of a case means the opening of a file whether on paper or on a computer disc needing available time combined with chair, table, office equipment, and electricity.

It is prudent to remember that in both literate and non-literate societies, the vast majority of relationships are conducted verbally. Few people conduct their interrelationships on paper and yet formal child-care becomes inevitably bureaucratic. Social welfare procedures require that all problems have to be worked out on paper and the solutions logically presented and acceptable to their superiors and professional colleagues.

The keeping of literate records suffers from one great drawback; they record what has happened at a certain time which has now passed. Most cultural systems that are not tied to creating legally enforceable social states, accept that there are no circumstances which remain the same for very long. The facts of a worrying situation in August are unlikely to be the same in September; and Buddhists or Hindus would accept this impermanency as reality. Carefully prepared manuals of customary law founder on the fact that any case which comes up is interpreted in terms of social situations rather than moral and legal precepts.

A series of visits to a situation of social welfare concern are in practice a series of different facts strung together by the professional visitor. The recorded life histories of the same individual at six monthly intervals may have only a tenuous relationship over key issues; they were not lying but are telling the last 'edition' which is currently the relevant one as far as their lives are concerned.

Parties to a difficulty over child welfare will act on the 'now' and say that the 'then' no longer applies. This knitting together of memory to keep itself up to date, does not sit comfortably with records on paper. Memory is always adjusting 
itself more or less effortlessly to the current circumstances in which it finds itself and thus to the outsider appears unreliable.

Most studies of memory are in fact checks on what can be remembered and do not cover the social demand factors. The fact is that 'the past is a foreign country, they do things differently there'(Hartley, 1953) so that people who are being questioned, have no need to use the past as a check on what they are saying now, as against what a social welfare professional has recorded on a previous occasion. Many people see their memories, consciously or unconsciously, as a way of adjusting to their present needs and not something which has the somewhat abstract quality of 'truth'.

There is in this perhaps an inverted social distance factor. The greater the professionalism, the longer the time that has to be spent in attempting to shrink the social distance between the subjects of child care supervision and those attempting to improve the situation. The professional personnel involved look, talk, dress and indeed smell differently to the objects of their attention; their hands which hold the pen and notebook are not care-worn.

It would seem therefore that due to these restricting factors on child care institutions and personnel, social welfare organisations are going to be involved with the worst situations which have gone beyond the limits of socially acceptable community controls; the child's care has become a public nuisance and the reactions to this are usually defensive.

It might be prudent to assume that in developing countries perhaps half of all children spends their lives in social situations which may contravene the laws of their country and the United Nations Convention on the Rights of Children.

\section{THE TENDENCY TO INSTITUTIONALISE}

It seems likely that the planning for action over the social welfare of children may have started with the assumption that this can only be done by the creation of institutional structures which developed in Western cultures over a long time and in particular social, economic and political circumstances. The United States has developed a overwhelming passion for legal processes while Japanese have perhaps achieved as much without having this preoccupation.

There is no inevitability for the necessity of institutions. An African criminologist from the
Ivory Coast attending a UNO conference in Denmark 1965 said with irony that institutions for delinquent children were one of the signs of a progressive modern state. However when they built one, there were no such children so that every month they had a 'chasse des enfants', a hunt for appropriately delinquent children.

Whatever institutions are created, their work will expand to fill up their time and become what might be called defensible space. Social welfare institutions are rarely cost-effective and probably are no better in many areas than what was achieved in the Asian and European Middle Ages or in the self-adjusting social situations in agricultural and urban subsistence communities. In many matters bureaucratic interventions are socially intrusive.

When a rule is legislated for the good of children and for the satisfaction of the legislators, it is often without following through its application. Much legislation has magical characteristics; it is supposed to work just because it has been passed by the appropriate legislative body and by legislators looking over their shoulders at their political masters. Of course it is shameful to see children of six years working and it should be stopped and when this is done what happens? When there are no national welfare schemes and their parents' or more likely their parent's wages are below any assessable national minimum, working children are a necessity. Why should it be illegal in towns in which children work in factories and building sites when they contribute to the subsistence farming of their families from the age of five scaring birds and taking water buffaloes to drink

Child prostitution is a disgrace for any community but are there any worthwhile financial alternatives for these boys and girls. It was once proposed to start adult education courses for bar girls in Mombasa. The Mother Superior of the local convent stated that even if this was successful, they would not be earning anything like the returns from prostitution. In Nairobi the more successful of such women have invested in substantial amounts of housing

Possibly it would be better to start from whatever a community accepts as reasonable in the circumstances, the climate of local rather than national shop-front opinion. It always has a shrewd idea of what it can afford socially, economically and at the end of the line morally. It is not the revolution of rising expectations which is the problem but that of rising disappointments.(Geertz, 1968: 32). 


\section{THE POSSIBILITY OF EFFECTIVE COMMUNAL STANDARDS}

Very little long-lasting change can be effected without the support of pervasive low-level public opinion that is created and sustained within a community rather than as a socially and politically imported requirement. This is certainly a slow process and the paradigm within which child care operates is not likely to change in any obvious way over decades

The metaphysical and social ideas of the Sukuma of Tanzania have not changed all that much over fifty years and it is into these that economic, social and political changes are fitted rather than the other way round (Wijsen and Tanner, 2002). Thus it would seem that the complex Chinese and Hindu paradigms from what are arguably much older and more pervasive patterns of thought and behaviour may still be operating in matters of child care as to what both adults and children should and should not do.

Any community has certain social practices into which its members are socialised and this is certainly an on-going process, largely out of sight of legislators and social welfare agencies. It is accepted generally that this is the way to behave and such patterns are followed correlating to the pressures of public opinion. If this is so there is always a narrow dividing line between imposed processes of social welfare and what is interpreted by the receivers of these ideas as no more than interference by outsiders.

In any community whether rural or urban there are influential people, not necessarily the educated or the more opinionated and vocal, who set at least some local standards. The pattern of ten house or apartment groupings which political parties and governments have on occasions instituted as in Tanzania, is one that is often socially viable. It is not too big for people to know each other. Chinese Communist officials have commented somewhat enviously that Christian groups which have created themselves, have been more socially effective than Party ones. Imposed systems of social change rarely work unless they coincide with pre-existing enabling social factors. There is one unfailing rule in instituting any measure of social change; think small and above all do not think in terms of resources which are not actually available.

\section{CONCLUSIONS}

It is suggested that by using the schema provided by Maslow's hierarchy of needs it is possible to assess the extent of the social welfare needs of children and the possibilities of change without the complications of cultural bias..

It is also suggested that the almost inevitable development of top-down welfare systems is short-sighted and economically impossible. In the conditions of economic restrictions in all developing societies, and which do not have adequate revenue the way forward should be the development of down-up possibilities of social welfare which would not involve long-term financial commitments.

The professionals in child-care in developing countries have the attention of politicians as their ideas slot into their policy ambitions which are shared with the standards aimed at by economically developed countries. Their professional status is in some ways detached and maintained apart from the numerically overwhelming nature of the problems facing their societies. For them to suggest that the people might create their own solutions without any network of enabling legislation and professional supervision to mitigate their own difficulties rather than have social workers making their social abilities less effective, comes up against the issue of professionals defending their own status as a primary need.

\section{REFERENCES}

Ferguson, J.1999. Expectations of Modernity. Myth and Meanings of Urban Life on the Zambian Copperbelt. Berkeley: University of California Press.

Geertz, C.1968. "Thinking as a moral act; ethical dimensions of anthropological fieldwork in New States". Antioch Review, 28(2)

Geertz, C. 2000. State of the Art. Anthropological Reflections on Philosophical Topics. New Jersey: Princeton University Press.

Hansen, K.T. 2003. "Target group intervention among youth in Zambian research". Anthropology in Action, 10(1): 34-41.

Hartley, L.P. 1953. The Go-between. London: Hamish Hamilton.

Maslow, A.H.1987. Motivation and Personality. New York: Harper \& Rowe.

Whyte, S.R. 1997. Questioning Misfortune. The Pragmatics of Uncertainty in Eastern Uganda. Cambridge: Cambridge University Press.

Wijsen, F. and R. Tanner. 2002. I am just a Sukuma. Amsterdam: Rodkopi. 